\title{
Neuroinflammation in Post-Ischemic Brain
}

\author{
Katarina Živančević • Darko Lović $\bullet$ Pavle R. Andjus • Lidija Radenović \\ Center for Laser Microscopy, Faculty of Biology, University of Belgrade, Serbia \\ * These authors contributed equally
}

Author for Correspondence: Lidija Radenović, Center for Laser Microscopy, Faculty of Biology, University of Belgrade, Serbia. Email: lidijar@bio.bg.ac.rs

Cite this chapter as: Živančević K, Lović D, Andjus PR, Radenović L. Neuroinflammation in Post-Ischemic Brain. In: Pluta R, editor. Cerebral Ischemia. Brisbane (AU): Exon Publications; 2021. Online first Aug 17.

Doi: https://doi.org/10.36255/exonpublications.cerebralischemia.2021.neuroinflammation

\begin{abstract}
Acute neuroinflammation occurring immediately after cerebral ischemia lasts for a few days. Cytokines and chemokines promote the migration of neutrophils and macrophages to the site of inflammation in the brain. Neuroinflammation lasting 2-6 weeks is known as subacute neuroinflammation, while chronic post-ischemic inflammation lasts for months or years. Macrophages, lymphocytes, and plasma cells predominate in chronic neuroinflammation, in contrast to neutrophils that predominate in acute neuroinflammation. In addition to their harmful impact on the ischemic brain, inflammatory mediators may also exert beneficial effects in stroke recovery. The role of secondary inflammatory cells in the pathophysiology of brain ischemia are still less understood. Late post-ischemic neuroinflammation leads to secondary damage of neuronal cells. In this chapter, the role of leukocytes, T cells, T regs, B cells, neutrophils, macrophages, microglia, astrocytes, cytokines, and transcription factors in the post-ischemic brain are discussed. Post-ischemic thrombo-inflammation and the role of platelets, recently considered as a part of the innate immune system, are also addressed. The current pharmacotherapy
\end{abstract}

In: Cerebral Ischemia. Pluta R (Editor). Exon Publications, Brisbane, Australia. ISBN: 978-0-6450017-9-2; Doi: https://doi.org/10.36255/exonpublications. cerebralischemia.2021

Copyright: The Authors.

License: This open access article is licenced under Creative Commons Attribution-NonCommercial 4.0 International (CC BY-NC 4.0) https://creativecommons.org/licenses/by-nc/4.0/ 
and future strategies for the treatment of neuroinflammation in post-ischemic brain as well as the limitations of translation between preclinical and clinical studies are presented.

Keywords: cerebral ischemia; immunomodulators; neuroinflammation; postischemic brain; transcription factors

\section{INTRODUCTION}

Stroke is the second leading cause of death and long-term disability. It is associated with significant clinical and socio-economic implications, emphasizing the need for elucidation of the pathophysiological mechanisms, and effective therapies $(1,2)$. Cerebrovascular illness, especially stroke, causes a large percentage (47-67\%) of disability-adjusted life years and deaths worldwide (3). Cerebral ischemia can be caused by an obstructed or significantly reduced blood flow to the brain that can have destructive effects on motor, behavioral, and cognitive functions as a result of molecular and cellular processes that lead to neurodegeneration (4). Following cerebral ischemia, neurons are deprived of oxygen and energy, leading to destructive effects on energy-dependent processes in neuronal cells (5). Immediately after cerebral ischemia, neurons are unable to preserve normal transmembrane ionic gradient and homoeostasis which leads to excitotoxicity, oxidative and nitrative stress, neuroinflammation, and apoptosis. These pathophysiological processes are harmful to neurons, glia, and endothelial cells (6-9), and as they are interlinked, trigger each other in a positive feedback loop that culminates in neuronal destruction (10). Additionally, ischemic stroke is accompanied by an increase in inflammatory events in the brain and periphery that contribute to further apoptosis and subsequent neurological damage (11).

Neuroinflammation is part of the complex biological response of the brain tissues to harmful stimuli, such as cerebral ischemia, and is a protective response involving immune cells, blood vessels, and molecular mediators. Neuroinflammation is defined as the activation of the brain's innate immune system in response to an inflammatory challenge and is characterized by a host of cellular and molecular changes within the brain (12). Research on neuroinflammation is challenging not only because it is difficult to study in humans, but also because neuroinflammation in animal models appears very different from the human disease. The function of neuroinflammation is to eliminate the initial cause of cell injury, clear out necrotic cells damaged from the cerebral ischemia and the inflammatory process, and initiate brain tissue repair. Acute neuroinflammation occurs immediately upon brain ischemic injury, lasting a few days. Cytokines and chemokines promote the migration of neutrophils and macrophages to the site of inflammation. Neuroinflammation lasting 2-6 weeks is designated subacute neuroinflammation, while chronic neuroinflammation lasts for months or years. Macrophages, lymphocytes, and plasma cells predominate in chronic neuroinflammation, in contrast to the neutrophils that predominate in acute neuroinflammation (12). Late post-ischemic neuroinflammation leads to secondary damage of neuronal cells. Once the cascade of events 
is initiated, the process of neuroinflammation can become overactivated, resulting in further cellular damage and loss of neuronal functions.

In the post-stroke brain, due to differential reductions of blood flow in different brain zones, a spectrum of severity is evident in the afflicted regions. Consequently, part of the brain tissue (the core) undergoes irreversible neuronal damage due to necrotic cell death, whereas the surrounding tissues contain recoverable and metabolically active cells (penumbra), in which cell death occurs less rapidly. The majority of developed therapeutic methods have focused on safeguarding neurons from the main pathophysiological processes, such as neuroinflammation and apoptosis, that might otherwise occur in the penumbra, and this area is the target for therapeutic agents (13-15). Changes due to loss of glucose and oxygen, including the triggering of a series of oxidative, biochemical, and hormonal reactions, culminating in microvasculature injury and blood-brain barrier (BBB) disruption, are well established. On the other hand, the role of secondary inflammatory cells in the pathophysiology of brain ischemia is still less understood. The inflammatory cascade is characterized by an immediate phase, which is initiated a few hours after stroke, but it can persist for days, weeks and years as a delayed tissue reaction to injury (16-18). In addition to their harmful impact to ischemic tissue damage, inflammatory mediators may also exert beneficial effects on stroke recovery (19). This chapter is intended to give an overview of the pathophysiological mechanisms and models of neuroinflammation in the post-ischemic brain, as well as to give an insight into the current therapeutic achievements.

\section{LEUKOCYTES, LYMPHOCYTES AND MACROPHAGES IN POST-ISCHEMIC BRAIN}

In post-ischemic neuroinflammation and subsequent neurovascular damage in the brain, leukocytes have been demonstrated to play an important role (20). Circulating leukocytes attach to vessel walls within hours after cerebral ischemia onset, causing migration and accumulation in ischemic brain tissue and transmigration across the BBB. This is followed by the production of pro-inflammatory mediators, causing secondary damage hampering tissue restoration inside the penumbra around the infarct core (21).

Neutrophils are the earliest leukocyte subtype to infiltrate the post-ischemic brain, causing an exacerbation of the ischemic injury by releasing additional inflammatory factors which are prominent effectors of the BBB disruption in ischemic stroke (20). The study by Gidday et al. (22) indicated that the neutrophilderived metalloproteinase MMP-9 contributes significantly to cerebral infarction. During reperfusion, MMP-9 released from degranulating neutrophils and recruited to the post-ischemic brain, promotes further neutrophil recruitment to the same sites in a positive feedback manner and causes BBB breakdown (22). Additionally, Stowe et al. (23) measured an increased number of extravascular neutrophil elastase-positive cells, as well as increased levels of tissue elastase protein and its activity, following transient middle cerebral artery occlusion (tMCAO). Both pharmacologic inhibition of neutrophil elastase and its genetic deletion 
significantly reduced infarct volume, BBB disruption, vasogenic edema, and leukocyte-endothelial adherence $24 \mathrm{~h}$ after tMCAO (23). In the permanent MCAO model (pMCAO), neutrophils reached peak at $12 \mathrm{~h}$ after insult onset (23). When neutrophil infiltration was inhibited in temporary cerebral ischemia, the infarct volume was significantly decreased $(24,25)$. Treatment with Hu23F2G (humanized monoclonal antibody that recognizes CD11/CD18 integrins) resulted in marked reduction of neutrophil infiltration, implicating that antagonism of neutrophil migration at the level of the CD11/CD18 integrin reduces cerebral ischemic injury (25). The study by Conolly et al. (24) confirmed that focal cerebral ischemia is followed by neutrophil influx and demonstrated that both neutrophil-deficient and transgenic ICAM-1 null mice are significantly resistant to cerebral infarction following ischemia and reperfusion (I/R), indicating that ICAM-1 plays a role in aggravating stroke pathogenesis.

On another note, the number of infiltrating leukocytes, $T$ cells, was shown to be increased in the ischemic brain parenchyma of Tenascin-C (TnC)-deficient mice compared with wild type mice, while the ischemic injury and neurological deficits were not affected. A mechanism was proposed in which the reduced microglia surveillance in TnC-deficient mice favors leukocyte accumulation in the ischemic brain (26). Infiltration of T cells was observed in both MCAO models at $24 \mathrm{~h}$, but pMCAO resulted in much more infiltrating T cells at 5 days, which is in accordance with the fact that $\mathrm{T}$ lymphocytes get recruited in the later stages of ischemic brain injury (27). In mice subjected to tMCAO or photothrombotic stroke, Feng et al. (28) found that lymphocyte infiltration persists in the ischemic brain until at least 14 days after the insult, during which brain infarct volume significantly diminished. However, Yilmaz et al. (29) demonstrated that T cells accumulate within the first $24 \mathrm{~h}$ in the ischemic brain, which might play a major role in influencing tissue inflammation and injury prior to the appearance of these cells in the extravascular space. Mice with $\mathrm{CD} 4+$ and $\mathrm{CD}^{-1-} \mathrm{T}$ cells exhibited comparable significant reductions in ischemia/reperfusion-induced leukocyte and platelet adhesions compared with wild type mice. These findings indicate that CD4+ and CD8+ T lymphocytes contribute to the inflammatory and thrombogenic responses, brain injury, and neurological deficit associated with stroke (29). Moreover, in our study, we confirmed T cell presence in ischemic brain parenchyma of the hippocampus and striatum, one year after the insult. We pointed out that persistent dysfunction of BBB may, in the long-term, lead to the infiltration of $\mathrm{T}$ cells that are predominantly of helper type (CD4+) and that such inflammatory processes are backed by microglial activity (30).

Modulation of regulatory T cells (Treg) cells is the target of various studies due to their neuroprotective properties. Liesz et al. (31) investigated the potential of histone deacetylase inhibition to enhance Treg potency for experimental stroke in mice. The number of Tregs was increased, and their immunosuppressive capacity and interleukin (IL)-10 expression were boosted. This resulted in reduced infarct volume and behavioral deficit after brain ischemia and attenuated cerebral proinflammatory cytokine expression (31). Xie et al. (32) injected rapamycin, an mTOR inhibitor, via the intracerebroventricular route $6 \mathrm{~h}$ after focal ischemic stroke in rats which resulted in an enhanced anti-inflammation activity of Tregs and decreased the production of pro-inflammatory cytokines and chemokines by macrophages and microglia. However, depletion of Tregs partially elevated macrophage/microglia-induced neuroinflammation after stroke. This data suggest that 
rapamycin can attenuate secondary injury and motor deficits after focal ischemia by enhancing the anti-inflammatory activity of Tregs acting to restrain post-stroke neuroinflammation (32). Recent studies have demonstrated that ischemia differentially regulates monocyte subsets, which directly affect ischemic stroke pathobiology and may have direct implications in ischemic stroke therapies (33).

$B$ cells play a crucial role in humoral immunity, and after being activated, produce antibodies that identify particular antigens (34). The role of B cells in postischemia brain is indistinctive $(35,36)$. Several studies demonstrated the potential protective role of B cells in post-ischemic brain $(37,38)$. Bodhankar et al. (39) provided evidence that IL-10-secreting B cells limit central nervous system (CNS) neuroinflammation and damage from ischemic stroke. In addition, B cell deficiency in mice caused larger infarct volumes, functional deficits, and higher mortality, while the adoptive transfer of highly purified wild type B cells into these mice decreased ischemic infarct size and enhanced neurological function, pointing out that the activity of IL-10-secreting wild type B cells mediated neuroprotection $(37,38)$. Those findings are supported in the study of Chen et al. (40), which showed that intrastriatal injection of B cells significantly limited infarct size after $\mathrm{MCAO}$ in B cell-deficient mice. However, these results are not in agreement with a study on the mouse stroke model where, due to increased BBB permeability, B cells take part in the post-ischemic brain injury, infiltrating into the brain parenchyma, and mediating neuroinflammation, finally resulting in a delayed poststroke cognitive impairment (41). According to Schuhmann et al. (42) B cells are probably less involved in early stroke evolution. Suggesting B cells involvement in later inflammatory processes following stroke, Doyle et al. (41) reported that these cells were undetectable for one week in post-stroke lesion, while extensive infiltration was detected seven weeks later and lasted up to 12 weeks following stroke, causing delayed deficits in long-term potentiation and cognition in mice. Due to those controversial outcomes, further studies are required to clarify B cell-related short- and long-term role in post-ischemic brain (35).

Macrophages are cells which are involved in later stages of neuroinflammatory reaction in brain ischemia. In a transient focal ischemia mouse model, Schilling et al. (43) demonstrated that resident microglia activation predates and dominates blood-derived macrophages and that their number peaked at day 7 and declined thenceforth. It has been shown that both blood-derived and brain-resident macrophages are distributed throughout the ischemic brain between 24 and $48 \mathrm{~h}$ after ischemia and may be detected for up to a week in mice following ischemic damage (33). Significant reduction in infarct volume and improved sensor-motor function one week after stroke was associated with decreased M1 CD40+ macrophages and increased alternatively activated, anti-inflammatory M2 microglia/ macrophage cells as well as reduced pro-inflammatory cytokine and chemokine levels in the post-ischemic brain (44).

\section{MICROGLIA IN POST-ISCHEMIC BRAIN}

Microglial cells are endogenous brain immune cells that represent 5-20\% of the neuroglial population. Upon brain ischemia, they undergo morphological and phenotypic changes, continuously changing and responding to local stimuli $(17,19)$. 
Microglia in the post-ischemic parenchyma move towards the ischemic lesion and remain in close proximity to the neurons in a process known as "capping," which aids in early identification and quick phagocytic clearance of dead neurons after neuronal death $(2,19)$.

In the post-ischemic brain, activated microglia become amoeboid and have a functional macrophage role releasing cytokines and secreting extracellular matrix metalloproteinases (MMPs) that could increase the permeability of the BBB, worsening post-ischemic injury (2). Depending on the signals encountered, activated microglia produce cytotoxic factors like reactive oxygen species, NO, glutamate and histamine, pro-inflammatory cytokines such as IL-1, TNF- $\alpha$, IL-6 and IFN- $\gamma$, in addition to neurotrophic and anti-inflammatory cytokines like IL-4, IL-10, BDNF, neurotrophin-3, -4 and -5 , and NGF (45). Moreover, other CNS cells such as astrocytes, neurons, oligodendrocytes, CNS-derived macrophages and mast cells contribute to the pro-inflammatory cytokine post-ischemic injury (17).

The activation of microglia in the post-ischemic brain in spontaneously hypertensive stroke-prone rats showed that the severity of ischemic injury may be correlated with the state of microglial activation (46). Also, in rats with transient focal cerebral ischemia, Sun et al. (47) confirmed that inhibition of the microglial activation via toll like receptor 4 (TLR4), alleviated neuroinflammation and reduced infarct volume. In the ischemic brain, ligustilid, a plant extract, decreased microglia/macrophage activation via inhibition of TLR4 expression, and extracellular signal-regulated kinase phosphorylation. These results demonstrated an early and direct neuroprotection by inhibiting TLR4/Prx6 signaling and subsequent immunoreactivity and neuroinflammation after cerebral ischemia (48). Zhou et al. (27) have found that activated microglia in the infarct brain region express CD14 receptors, suggesting a microglial activation mechanism. On the other hand, Jin et al. (49) showed that depletion of microglia via their inhibitor PLX3397 dramatically promoted the production of inflammatory mediators, leukocyte infiltration, and cell death during brain ischemia.

In our long-term survival post-ischemic study, we revealed a chronic effect of global cerebral ischemia on the neuroinflammatory reaction sustained by microglia and astrocytes in the rat brain even two years after the insult (18). Microglial activation was found in CAl and CA3 areas, and the motor cortex, while significant activation of astrocytes was revealed in hippocampal CAl and CA3 areas and dentate gyrus, motor and somatosensory cortex, striatum and thalamus. In the latter, specifically in sensitive brain areas, microglia and astrocytes showed significant activation, while in the resistant brain areas only astrocytes were activated, suggesting that less intensive neuroinflammation is present in brain areas resistant to ischemia (18).

\section{ASTROCYTES IN POST-ISCHEMIC BRAIN}

Together with microglia, astrocytes represent the major immunocompetent cells of the CNS containing a number of receptors involved in innate immunity, such as toll-like receptors (TLR), nucleotide binding oligomerization domains, doublestranded RNA-dependent protein kinase, scavenger receptors, mannose receptor, and components of the complement system (50). They are involved in the 
maintenance of the CNS (19). Immune response could be modulated via astrocytes by inhibiting $\mathrm{T}$ cells and monocyte activation. Some reactive astrocytes change into nonprofessional phagocytes after an ischemic stroke and "clean up" the infarct region (50). In physiological conditions, astrocytes consume excessive glutamate from extracellular space and convert it to glutamine for neural reuse, and upon brain injury their capability for uptake may be impaired (2). The role of astrocytes in preventing excitotoxic glutamate elevation was confirmed in tMCAO rat model (51). The findings suggest that the modulation of glutamate-induced astrocyte death early after reperfusion may be a novel mechanism of FK506mediated neuroprotection in ischemia.

Brain ischemia is followed by specific structural and functional changes, the so-called "reactive gliosis," characterized by activated brain astrocytes resulting in increased glial fibrillary acidic protein (GFAP) expression (20). In the photothrombotic rat ischemic model, a substantial astroglial response was developed after ischemia (52). This increment was detectable up to 60 days after the infarct. In the hippocampus, GFAP elevation was also found, 1 day after photothrombosis, while in amygdala it was demonstrated 4 days after the lesion. Moreover, in our study which included post-ischemic rats, significant activation of astrocytes was revealed in hippocampal CA1 and CA3 areas and dentate gyrus, motor and somatosensory cortex, and striatum and thalamus, even 2 years after the insult (18).

Additionally, astrocytic activation after stroke may provide factors promoting the recovery processes in the whole brain (52). Inflammatory substances, including cytokines, chemokines, and inducible nitric oxide synthase (iNOS), can also be secreted by astrocytes (20). iNOS expression was found in reactive astrocytes of the hippocampus 10 min after temporary global ischemia, but not in unaffected hippocampal astrocytes (53). Having in mind that astrocytes are believed to bridge interactions between infiltrating lymphocytes and neurons during brain ischemia and that IL-15 has been found dramatically up-regulated in astrocytes of a mice model of transient focal brain ischemia, Li et al. (54) generated a GFAP promotercontrolled IL-15-expressing transgenic mouse (GFAP-IL-15tg) line. This animal model showed enlarged brain infarcts, and exacerbated impairments after cerebral ischemia, indicating that astrocytic IL-15 may aggravate post-ischemic brain injury by propagating CD8+ T and NK cell-mediated responses.

\section{CYTOKINES IN POST-ISCHEMIC BRAIN}

Cytokines are small pleiotropic polypeptides that regulate both adaptive and innate immune responses, normally expressed at very low levels (21). As already mentioned, after ischemic stroke, pro- and anti-inflammatory cytokines' release rapidly increases throughout the brain $(20,55)$. Interleukin-1 $\beta$ (IL-1 $\beta$ ), tumor necrosis factor- $\alpha$ (TNF- $\alpha$ ), IL- 6 , IL-10, interferon- $\beta$ (IFN- $\beta$ ), and transforming growth factor- $\beta$ (TGF- $\beta$ ) are key mediators of BBB influence in post-ischemic brain. Whereas IL- $1 \beta$ and TNF- $\alpha$ appear to exacerbate cerebral injury, IL-10, IFN- $\beta$, and TGF- $\beta$ may have neuroprotective role $(56,57)$. In post-ischemic brain, activated microglia and macrophages mainly produce TGF- $\beta 1$, while astrocytes and neurons primarily generate TGF- $\beta 2$ (21). 
As suggested by Denes et al. (58), both central and peripheral IL-1 $\beta$ significantly contributes to ischemic injury as well as to BBB breakdown. In addition, IL-1 $\beta$ and TNF- $\alpha$ mRNA are increased $3 \mathrm{~h}$ after ischemia, while TNF- $\alpha$ protein levels rise dramatically from $6 \mathrm{~h}$ to 5 days following ischemia onset (21). In correlation with this, the results of TNF- $\alpha$ inhibition via a monoclonal antibody showed significant reduction of ischemic brain damage (21). IL-10 could have a potential protective role in ischemic injury since the infarct volume and neurological deficits were slightly increased in IL-10-deficient mice after pMCAO (59). In addition, noticeable reduction of infarct volume, and leukocyte and macrophage infiltration were found after injection of adenoviral vectors encoding the human IL-10 gene into the lateral ventricle in post-ischemic brain (60). IFN- $\beta$ also showed reduction of infarct volume after ischemic stroke in rats by suppressing the infiltration of inflammatory cells into the parenchyma (61). Moreover, in the mice ischemia model, administration of TGF- $\beta 1$ reduced infarct volume, improved functional recovery, and promoted neurogenesis (62). Finally, a significant reduction in infarct volume as well as a decreased level of inflammatory chemokines were achieved by TGF- $\beta 1$ overexpression (63).

\section{TRANSCRIPTION FACTORS IN POST-ISCHEMIC BRAIN}

Transcription factors play a crucial role in controlling inflammatory gene expression in post-ischemic brain (64-71). Activation of hypoxia inducible factor-1, the cAMP-response element binding protein (CREB), c-fos, peroxisome proliferatoractivated receptor (PPAR) PPAR $\alpha$, PPAR $\gamma$, and p53 protein is known to prevent ischemic neuronal damage and/or promote ischemic tolerance. However, the inductions of interferon regulatory factor 1 (IRF-1), as well as the activation of the transcription factor-2, signal transducer and activator of transcription 3 (STAT3), NF-kB, early growth response-1 (Egr1), and C/EBP $\beta$ promotes neuroinflammation and neuronal death after cerebral ischemia (71). Moreover, IRF-1 gene expression was markedly upregulated within $12 \mathrm{~h}$ of MCAO in mice. The expression reached a peak 4 days after ischemia and was restricted to the ischemic regions of the brain (64).

Activation of NF- $\mathrm{KB}$ occurs after MCAO in mice, and the inhibition of NF- $\mathrm{kB}$ activity resulted in smaller infarct volume (65). Furthermore, following focal ischemia, mice deficient in NF-kB subunit p50 were shown to develop smaller infarct volume, suggesting detrimental consequence of NF- $\mathrm{kB}$ activation. In addition, reduced infarct volume, enhanced neurological function, and reduced activation of many inflammatory genes in Egrl null mice confirm that Egrl is a significant contributor of neuroinflammation and neuronal damage in post-ischemic brain (65). Satriotomo et al. (68) showed that following transient focal ischemia, JAK2 and STAT3 phosphorylation were increased in the microglia/macrophages. Thus, treating ischemic rats with either a JAK2 phosphorylation inhibitor (AG490) or a STAT3 siRNA prevented neuroinflammation, and secondary brain damage. Moreover, in the post-ischemic brain JAK-STAT activation leads to increased expression of cytokine signaling-3 suppressor, which is a negative feedback regulator of IL-6 signaling (68). Kapadia et al. (67) observed curtailed inflammatory responses characterized by decreased ICAM-1 immunopositive vessels, and 
smaller number of extravasated neutrophils and macrophages in C/EBP $\beta$ null mice following tMCAO. It was found that many inflammatory and neuronal damage inducing-genes were less pronounced in $\mathrm{C} / \mathrm{EBPb}$ null mice brains, suggesting a significant role of C/EBP $\beta$ in post-ischemic neuroinflammation and brain damage (67). In contrast, PPAR $\alpha$ showed beneficial effects, where treating rats with the PPARa antagonist WY14643 increased oxidative stress, iNOS, and ICAM-1 expression following transient ischemia (66). Interestingly, neuroprotection via PPARY agonists was observed in hypertensive as well as diabetic rodents subjected to focal ischemia. PPAR $\gamma$ agonists prevented post-ischemic inflammatory gene expression, induced antioxidant gene expression, and decreased infarction and neurologic dysfunction (70). The overview of animal models for the study of neuroinflammation in the post-ischemic brain is presented in Table 1.

\section{TABLE 1 Overview of animal models for the study of neuroinflammation in the post-ischemic brain}

\begin{tabular}{lllc} 
Animal & Type of ischemia & Studied mechanism & Reference \\
\hline Rat & TFCI & Microglial activation & $(46)$ \\
Rat & TFCI & Microglial activation & $(47)$ \\
Mouse & TFCI & Microglial activation & $(27)$ \\
Rat & TFCI & Microglia/macrophage activation, leukocytes infiltration & $(48)$ \\
Rat & GCI & Astrocytes and microglia activation & $(18)$ \\
Mouse & TFCI & Microglial depletion-induced exacerbation & $(49)$ \\
Mouse & TFCI & IL-1 $\beta$ expression & $(58)$ \\
Mouse & TFCI & TNF- $\alpha$ expression & $(56)$ \\
Rat & G/FCI & IL-10 gene effect & $(60)$ \\
Mouse & PFCI & IL-10 deficiency & $(59)$ \\
Rat & PFCI & IFN- $\beta$ anti-inflammatory properties & $(61)$ \\
Mouse & TFCI & TGF- $\beta 1$ administration & $(62)$ \\
Mouse & TFCI & TGF $\beta 1$ overexpression & $(63)$ \\
Rat & Photothrombotic & Microglial/astroglial response & $(52)$ \\
& ischemic insult & & \\
Rat & TGCI & Expression of iNOS, NADPH diaphorase by reactive & $(53)$ \\
& & astrocytes & $(51)$ \\
Rat & TFCI & Modulation of glutamate-induced astrocyte death & $(54)$ \\
Mouse & TFCI & Astrocyte-derived IL-15 influence & $(22)$ \\
Mouse & TFCI & MMP-9 promotes further neutrophil recruitment and & \\
Mouse & T\&PFCI & Influence of neutrophil elastase & $(24)$ \\
Mouse & TFCI & Impact of blocking neutrophil infiltration & \\
& & &
\end{tabular}




\section{TABLE 1 Overview of animal models for the study of neuroinflammation in the post-ischemic brain (Continued)}

\begin{tabular}{|c|c|c|c|}
\hline Animal & Type of ischemia & Studied mechanism & Reference \\
\hline Rabbit & $\mathrm{TFCI}$ & Impact of blocking neutrophil infiltration & (25) \\
\hline Mouse & TFCI & $\begin{array}{l}\text { The effects of TnC deficiency on ischemic injury and } \\
\text { leukocyte infiltration }\end{array}$ & (26) \\
\hline Mouse & $\mathrm{TFCI}$ & Lymphocyte infiltration & (28) \\
\hline Rat & GCI & $\mathrm{T}$ cell infiltration & (30) \\
\hline Mouse & $\mathrm{TFCI}$ & T cells accumulation & (29) \\
\hline Mouse & $\mathrm{FCI}$ & Histone deacetylase inhibition enhance Treg potency & (31) \\
\hline Rat & TFCI & Treg activity & (32) \\
\hline Mouse & TFCI & Macrophages & (43) \\
\hline Rat & TFCI & $\begin{array}{l}\text { Pro-inflammatory cytokine and chemokine levels, M1 } \\
\text { CD40+ macrophages and anti-inflammatory M2 } \\
\text { microglia/macrophage cells' response }\end{array}$ & (44) \\
\hline Mouse & TFCI & Pro-inflammatory role of IRF1 & (64) \\
\hline Mouse & PFCI & Pro-inflammatory role of NF-kB & (65) \\
\hline Rat & $\mathrm{TFCI}$ & Pro-inflammatory role of STAT3 & (68) \\
\hline Mouse & TFCI & Pro-inflammatory role of C/EBP $\beta$ & (67) \\
\hline Rat & TFCI & PPAR $\alpha$ anti-inflammatory role & (66) \\
\hline Rat & TFCI & PPAR $\beta / \delta$ anti-inflammatory role & (69) \\
\hline Rat/ & TFCI & Anti-inflammatory role of PPAR $\gamma$ & (70) \\
\hline Mouse & TFCI & Protective role of B cells (IL-10) & (38) \\
\hline Mouse & TFCI & Protective role of B cells (IL-10) & (37) \\
\hline Mouse & TFCI & Protective role of B cells (IL-10) & $(40)$ \\
\hline Mouse & TFCI & Protective role of B cells (IL-10) & (39) \\
\hline Mouse & PFCI & Long-term potentiation and cognition impairment & (41) \\
\hline Mouse & $\mathrm{TFCI}$ & Leukocyte adhesion responses attenuated & (29) \\
\hline Mouse & TFCI & Depletion of B cells & (42) \\
\hline
\end{tabular}

GCI-global cerebral ischemia; PFCI-permanent focal cerebral ischemia; TFCI-transient focal cerebral ischemia.

\section{THERAPY FOR NEUROINFLAMMATION IN POST-ISCHEMIC BRAIN}

Guidelines of good clinical practice for stroke management provide direction for medical and pharmacological interventions, with regards to the cause of stroke and maintaining vital functions and physiological parameters in the acute and 
subacute phases, while for the chronic phase, they provide preventive measures to control comorbidities (such as high blood pressure, elevated cholesterol and blood sugar levels, atrial fibrillation, coagulopathies, etc.). These guidelines consider, but do not recommend, neuroprotective agents in the acute, subacute, or chronic phases of cerebral ischemia, because there is currently insufficient evidence in clinical studies to support such recommendations. In particular, there are no guidelines suggesting the treatment of neuroinflammation as a separate entity that contributes to neurodegeneration in cerebral ischemia (72-74). For now, the potential use of neuroprotective and anti-neuroinflammatory agents are based on the results of preclinical studies in cerebral ischemia animal models, as well as on scarce data from clinical studies. Different therapeutic approaches and pharmacological candidates for the treatment of neuroinflammation in post-ischemic brain are presented in Figure 1.

As cerebral ischemia is characterized by a chain of reactions of several complementary processes which include excitotoxicity, oxidative stress, neuroinflammation, activation of proapoptotic factors, disruption of ionic homeostasis and increased permeability of BBB, the logical approach for therapy would be an adjuvant therapy that would include pharmacological candidates that act on all of these phenomena. Choudhary et al. (75) suggested the use of a neuroprotective cocktail consisting of different therapeutic approaches and pharmacological candidates that would target different phenomena of cerebral ischemia contributing to neurodegeneration. Although individual drug candidates have given promising results in preclinical studies, the effects of combined therapy should be examined

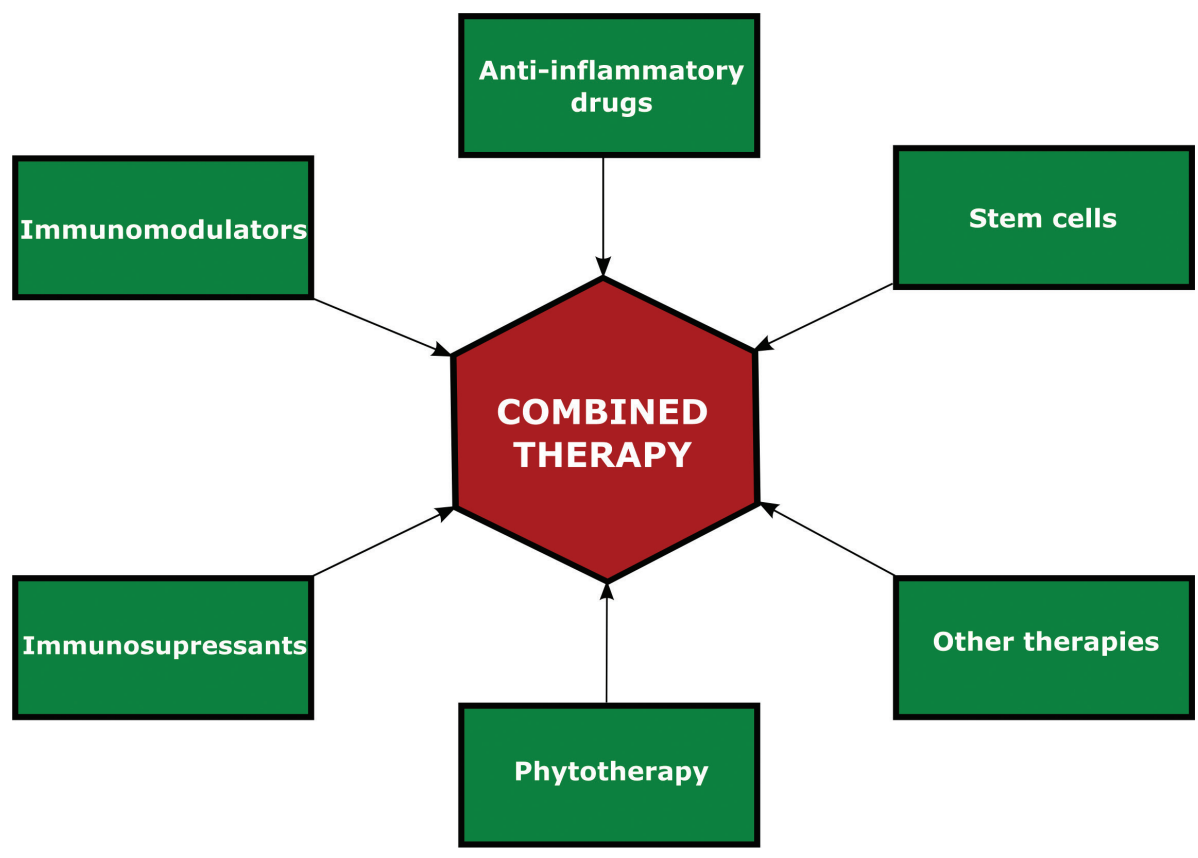

Figure 1. Different therapeutic approaches and pharmacological candidates for the treatment of neuroinflammation in post-ischemic brain. 
in preclinical models that faithfully reflect the state of cerebral ischemia. It should be noted that younger animals without co-morbidities were often used in preclinical studies, their post-ischemic recovery being faster and more complete than in the older animals, which makes translation questionable. Hence, the critical factor for translation is the fact that cerebral ischemia mainly affects older people who have other co-morbidities (76). Modulation of inflammatory pathways has been postulated as a robust strategy in altering the secondary cell death of the ischemic brain $(77,78)$. Inflammatory responses intrinsic to the brain or derived from peripheral organ-specific infiltrating cells, including neutrophils, T cells, and monocytes/macrophages, mediate the secondary neurodegeneration seen in stroke (79). Studies examining therapeutic approaches for the treatment of neuroinflammation included pharmaceuticals targeting microglia, pro-inflammatory and anti-inflammatory cytokines, pro-inflammatory transcription factor NF-kB, high mobility group 1 proteins, the endocannabinoid system, and metalloproteinases (80).

\section{Immunomodulators}

As stated before, starting from the first minutes of the onset of cerebral ischemia, until a few weeks later, various immune cells are activated, and their activation is mediated by various cytokines, chemokines, and membrane receptors on endothelial cells. Immunomodulatory therapeutics that have shown the most significant effects in preclinical models and clinical trials act on these factors. Such factors with the corresponding drugs (in brackets) are the complement system (IVIG), TNF- $\alpha$ (Etanercept), IL-1 $\beta$ (Anakinra), chemokines (JWH-133), MMPs (minocycline), ICAM-1 (Enlimomab) (81). Neutrophils and microglia are activated in the first minutes of brain ischemia and can be inhibited by recombinant neutrophil inhibitory factors UK-279 and UK-276. Microglia and macrophages that are activated after 2-3 days can be inhibited by minocycline and edaravon (81). A few days after stroke, Thl and Th17 (CD4+ $\mathrm{T}$ cell subset that produces IL-1/IL-17) cell response occurs, and may be suppressed by fingolimod or natalizumab, as well as by adoptive transfer of Treg cells. In the weeks after stroke, B lymphocytes take over the predominant role in long-lasting neuroinflammation which can be reduced by rituximab or by adoptive transfer of Breg cells (81).

\section{Anti-inflammatory drugs}

In transient and permanent MCAO animal models, as well as in global ischemia models, it has been shown that non-selective cyclooxygenase inhibitors (acetylsalicylic acid, ibuprofen, piroxicam, indomethacin) and the so-called coxibs (celecoxib, NS398, SC-58125, SC-58236) reduce the infracted area and improve functional recovery after the insult (82). In addition to coxibs, the effects of small molecules acting as agonists or antagonists of specific prostaglandin receptors were investigated in these models. The most significant effects were shown by agonists of DP1 receptor (BW245C), EP4 receptor (ONO-AE1-329), IP receptor (beraprost), and antagonists of DP2 receptor (CAY10471), EP1 receptor (SC51089, ONO- 8713), EP2 receptor (benzoxazepine, TG6-10-1), 
EP3 receptor (ONO-AE3-240), FP receptor (AL-8810), and TP receptor (SQ29548) (82). However, the blockade of the cyclooxygenase-prostaglandin cascade has both protective and harmful effects (82). Thus, it could be concluded that COX-2 inhibitors may be suitable as an adjuvant in the treatment of acute and subacute ischemic stroke, but not for the treatment of delayed cerebral ischemia. Therefore, the future strategy for pharmacological therapy should go in the direction of finding selective antagonists or agonists of appropriate prostaglandin receptors that will act on this cascade. It would be best to use a therapeutic cocktail consisting of different antagonists and agonists of these receptors that have complementary action. For example, it has been observed that combined antagonism of Gq-coupled prostaglandin receptors (EP1, FP and TP) significantly reduce the level of ischemia, albeit not so efficient when used separately (82).

Studies on thrombo-inflammation were performed with drugs acting on platelet aggregation, coagulation factors (von Willebrand factor and its activating protease ADAMTS-13 and coagulation factor FXII), contact-kinin pathway, and platelet receptors (80). Rawish et al. (83) provided a more detailed overview of the influence of platelets on the occurrence of neuroinflammation through a comparative study of preclinical models of cerebral ischemia (MCAO model), neuroinflammation (EAE model), and neurodegeneration (animal models of Alzheimer's disease), as well as clinical studies. They emphasize the importance of platelet interaction with blood vessel endothelium and the cells that make the neurovascular unit (BBB) (84), as well as the interactions with the complement system and cells of the innate and acquired immunity. The most important candidates for translational and clinical studies are the antiplatelet drugs acetylsalicylic acid (inhibits COX-1 and COX-2 and thromboxane A2) and clopidogrel (inhibits P2Y12 receptors on platelets), revacept (blocks the activation and aggregation of platelet progenitor - GPVI), caplacizumab (inhibits the interaction between von Willerbrand factor multimer and glycoprotein Ib - GPIb on platelets), vorapaxar (inhibits PAR-1), BMS-986141 (inhibits PAR-4), cilostazol (inhibits phosphodiesterase), and ibulast (inhibits phosphodiesterase) (80). The mechanism of thromboinflammation in cerebral ischemia definitely deserves attention, as do platelets, which have recently been considered as a part of the innate immune system. Antiinflammatory drugs are logical step in the treatment of post-ischemic neuroinflammation. Indomethacin and minocycline have anti-inflammatory properties that can potentiate the M2 anti-inflammatory phenotype of microglia and suppress the Ml pro-inflammatory phenotype which reduces neurodegeneration and can induce neurogenesis, as shown in various in vitro and in vivo models of ischemia (85).

\section{Glibenclamide}

Glibenclamide is a sulfonylurea derivative used in the treatment of diabetes to lower blood sugar levels. Rodent models of ischemic and hemorrhagic stroke have been shown to benefit from the sulfonylurea receptor 1 conjugated with transient receptor potential melastatin 4 (Surl-Trpm4 receptor) inhibition, which reduces levels of cellular swelling, cell necrosis, microvascular dysfunction, ionic and vasogenic edema formation, secondary hemorrhage, and neuroinflammation (86). 
The decrease in neuroinflammation is based on the effect of glibenclamide on $\mathrm{K}_{\text {ATP }}$ (Surl-Kir6.2), which leads to a reduced reactivity of microglial cells. Retrospective clinical studies, as well as a prospective phase II pilot study, provide promising results in the use of glibenclamide after cerebral ischemia (86). In a model of cardiac arrest induced by asphyxia with concomitant cardiopulmonary resuscitation, glibenclamide was shown to exert anti-neuroinflammatory effects by downregulating the NLRP3 inflammatory pathway (87).

\section{Statins}

Statins are a group of drugs that are primarily used to lower blood cholesterol levels in patients who have suffered a heart attack or stroke, primarily because they reduce the process of atherosclerosis, but also because of other pleiotropic effects. Based on these pleiotropic effects, such as decreased production of proinflammatory cytokines and pro-inflammatory transcription factors, decreased endothelial reactivity by lowering NO production, decreased blood coagulation and decreased ROS production, it can be assumed that these drugs may reduce neuroinflammation in cerebral ischemia (88). Statins, as proven safe drugs for lifelong use, can certainly be recommended as a lifelong prevention measure in the patients who have suffered a stroke.

\section{Immunosuppressants}

The use of immunosuppressants for the treatment of neuroinflammation after cerebral ischemia is a logical therapeutic approach. Although in vitro and in vivo models of cerebral ischemia have shown that corticosteroids, cyclosporin A, tacrolimus, rapamycin, mycophenolate mofetil and minocycline may have neuroprotective effects in cerebral ischemia (89), the benefits of systemic immunosuppression in clinical trials are not provided in the treatment of ischemic stroke (90), nor in the treatment of hemorrhagic stroke (91). Immunosuppressants, especially those from the group of corticosteroids, have a wide range of immunosuppressive effects as they inhibit regulatory $\mathrm{T}$ and $\mathrm{B}$ lymphocytes and other immune mechanisms in post-ischemic neuroinflammation. Patients who have suffered a stroke often have pathophysiological immunosuppression and are thus susceptible to infections, hence the immunosuppression strategy should be directed towards the use of immunomodulators that will more discreetly target immune mechanisms.

\section{Ceftriaxone}

Drug repurposing is one of the approaches by which therapy can be quickly extended to new indications for which the drug was not originally intended. Such is the case with the cephalosporin antibiotic ceftriaxone, which has shown several neuroprotective effects in preclinical studies: up-regulation of GLT-1 receptor expression that reduces glutamate excitotoxicity, increase of BDNF levels, regulation of oxidative stress, and induction of anti-inflammatory effects (92). Ceftriaxone has been shown in various cerebral ischemia animal models to reduce NO levels, suppress microglial activation, and inhibit IL- $1 \beta$ production (92). It is often the case that patients after stroke show signs of systemic immunosuppression, and are more susceptible to respiratory, urinary and other infections. Ceftriaxone as a 
broad-spectrum antibiotic can thus be used as an adjunct to existing therapy due to its neuroprotective action and antibiotic properties.

\section{Melatonin}

Melatonin is a hormone of the pineal gland that plays a role in the circadian rhythm, but it has also been shown to have neuroprotective properties, primarily due to its antioxidant, anti-inflammatory, and anti-apoptotic effects (93). In cerebral ischemia models and in a few clinical studies, melatonin has been shown to exert neuroprotective effects via melatonin MT1 and MT2 receptors found in all brain regions (94). Melatonin can be used in therapy alone, or in combination with stem cells, because they also express MT1 and MT2 receptors that are important for their activation (95). In addition, melatonin has anti-neuroinflammatory effects, where in vitro and in vivo ischemia studies have shown that it reduces the levels of IL-1 $\beta$, IL- 6, TNF $\alpha$, and favors the M2 phenotype of microglia. Because of all these effects, melatonin can be considered as a safe adjuvant in post-ischemic neuroinflammation $(95,96)$.

\section{Agmatine}

Agmatine is an endogenous active polyamine, with multiple biological functions such as promoting cell growth and proliferation, synthesis of proteins and nucleic acids, differentiation of immune cells, and regulation of inflammatory reactions $(97,98)$. In vitro and in vivo models have shown different neuroprotective effects of agmantine in neurodegenerative and neuropsychiatric disorders, as well as in cerebral ischemia due to its neuromodulation, reduction of neuroinflammation, and apoptosis (99-101). Agmatine's anti-inflammatory effects are fulfilled by reducing the levels of NO, IL-1 $\beta$, IL-6, TNF- $\alpha$, and NF-kB $(98,102)$. Protective effects in the post-ischemic brain are achieved by the reduction of cerebral edema and by the inhibition of metalloproteinases that disrupt the BBB function $(98,103)$. Due to a number of neuroprotective effects, agmatine has a very good translational potential for clinical studies that could confirm its effectiveness in many neurological disorders.

\section{Gasdermin D}

Pyroptosis is an inflammatory form of programmed cell death, activated by caspase $1,-4,-5$, and -11 , with Gasdermin D as the end product of this process. This activation, in addition to apoptosis, also leads to the release of proinflammatory cytokines that provoke further neuroinflammation. Thus, Gasdermin D suppression is a potential new strategy for the treatment of neuroinflammation after stroke (104).

\section{Stem cells therapy}

Cell-based and pharmacological anti-inflammatory therapies have been shown to improve stroke outcome (105-109). Stem cells secrete various anti-inflammatory, anti-oxidative, and anti-apoptotic factors that can be neuroprotective. Systemic inflammatory response is known to be a key pathological component in 
exacerbating secondary post-stroke cell death (110), and stem cell transplantation appears to be a promising therapy to attenuate this system-wide immune response and ameliorate stroke outcomes. Numerous preclinical studies on cerebral ischemia animal models, and a few clinical studies, have shown anti-neuroinflammatory effects of stem cells (111). The use of stem cells shows benefits in the acute, subacute, and chronic phases of post-ischemia, depending on dose and the route of administration (111). However, there are still questions about optimal cell type, dosage, mechanism of action, route of administration, and long-term safety. $(112,113)$. The efficacy of cell therapies is also related to the extent to which the cells exhibit trophic factors, and other secreted therapeutic molecules (antiinflammatory chemokines and cytokines) (114). While substantial progress has been made in neuroregenerative stem cell therapies, further investigation is needed to optimize them for clinical use. Advances in induced pluripotent stem cell technology have the potential for development of the so-called disease-in-adish personalized models to study disease mechanisms and develop new therapeutic approaches (115). Different cell types can also be produced for therapeutic use. A number of clinical trials investigating stem cell therapy for stroke are now ongoing. Clinical challenges may include more complex situations with comorbidities which can affect cell therapy.

\section{Phytotherapy}

Many pharmacologically active substances derived from plants exhibit neuroprotective effects due to their antioxidant, anti-inflammatory and neuromodulatory properties. Thus, active groups from lignans and neolignans, flavonoids, polyphenols, triterpenoids, phytoestrogens and coumarins inhibited production of $\mathrm{NO}$, a significant pro-inflammatory factor in the development of neuroinflammation (116). Mircetin, a polyphenol from flavonoids, acts as an anti-neuroinflammatory by inhibiting pro-inflammatory cytokines (IL-1, TNF- $\alpha$ ), NF-kB, COX-2, and NLRP3 receptors which mediate microglial activation (117). Preclinical studies with sulforaphane, an isothiocyanate from green vegetables, have shown neuroprotective effects in Alzheimer's disease, Parkinson's disease, multiple sclerosis as well as in cerebral ischemia (118). These neuroprotective effects are primarily due to the antioxidant and anti-inflammatory properties of sulforaphane. In models of focal cerebral ischemia, both transient and permanent MCAO, it has been shown that sulforaphane can reduce neuroinflammation by lowering phosphorylation and nuclear translocation of NF-kB, decreasing pro-inflammatory cytokines production, and reducing NLRP3 inflammasomes production due to the induction of nuclear factor erythroid 2-related factor 2 (Nrf2) and heme oxygenase 1 (HO-1) (118). In numerous preclinical studies, lycopene, an aliphatic hydrocarbon from carotenoids, demonstrated antioxidant, anti-inflammatory, and anti-proliferative properties. In rodent models of cerebral ischemia, it reduced neuroinflammation by increasing $\mathrm{Nrf} 2$ and $\mathrm{HO}-1$, inhibiting mitogen-activated protein kinase and by lowering NO, iNOS and IL-6 production. Curcumin is a polyphenolic ingredient from the plant Curcuma longa. Its antioxidant and anti-inflammatory effects have been shown in various CNS diseases $(119,120)$ and it was shown to easily pass the BBB. It binds and disaggregates oligomers and fibrils of amyloid proteins and increases amyloid clearance. In addition, it stimulates neurogenesis, and can be taken in relatively high doses without side effects. Among the proven curcumin 
anti-inflammatory effects are the reduction of BBB permeability, glial activation, the reduction of IL- 6 , TNF- $\alpha$, and iNOS (121). Many active agents from plants have shown great potential for translation, but their clinical application should be approached with caution especially in terms of interactions with other drugs that is often neglected.

\section{CONCLUSION}

For the treatment of post-ischemic neuroinflammation, the focus should be on candidates that selectively act on immune mechanisms such as immunomodulators and prostaglandin receptor inhibitors. Stem cells are also candidates with great potential for translation because, in addition to anti-inflammatory effects, they also exhibit neuroregenerative effects. Combined cellular and pharmaceutical therapy approach should also be considered. For many pharmacological candidates, there is strong evidence of efficacy both in vitro and in vivo, and therefore, there is a basis for translation from bench to bedside. The best approach for the pharmacotherapy of cerebral ischemia would be the use of a combination of drugs that would act on excitotoxicity, oxidative stress, apoptosis, and neuroinflammation.

\section{REFERENCES}

1. Gladstone DJ, Black SE, Hakim AM. Toward wisdom from failure: Lessons from neuroprotective stroke trials and new therapeutic directions. Stroke. 2002;33(8):2123-36. https://doi.org/10.1161/01. STR.0000025518.34157.51

2. Pluta R, Januszewski S, Czuczwar SJ. Neuroinflammation in post-ischemic neurodegeneration of the brain: Friend, foe, or both? Int J Mol Sci. 2021;22(9)4405. https://doi.org/10.3390/ijms22094405

3. Feigin VL, Krishnamurthi R V., Theadom AM, Abajobir AA, Mishra SR, Ahmed MB, et al. Global, regional, and national burden of neurological disorders during 1990-2015: a systematic analysis for the Global Burden of Disease Study 2015. Lancet Neurol. 2017;16(11):877-97. https://doi. org/10.1016/S1474-4422(17)30299-5

4. Khoshnam SE, Winlow W, Farzaneh M, Farbood Y, Moghaddam HF. Pathogenic mechanisms following ischemic stroke. Neurol Sci. 2017;38(7):1167-86. https://doi.org/10.1007/s10072-017-2938-1

5. Murphy TH, Li P, Betts K, Liu R. Two-photon imaging of stroke onset in vivo reveals that NMDA-receptor independent ischemic depolarization is the major cause of rapid reversible damage to dendrites and spines. J Neurosci. 2008;28(7):1756-72. https://doi.org/10.1523/JNEUROSCI.5128-07.2008

6. Ouyang YB, Voloboueva LA, Xu LJ, Giffard RG. Selective dysfunction of hippocampal CAl astrocytes contributes to delayed neuronal damage after transient forebrain ischemia. J Neurosci. 2007;27(16):4253-60. https://doi.org/10.1523/JNEUROSCI.0211-07.2007

7. Besancon E, Guo S, Lok J, Tymianski M, Lo EH. Beyond NMDA and AMPA glutamate receptors: emerging mechanisms for ionic imbalance and cell death in stroke. Trends Pharmacol Sci. 2008;29(5): 268-75. https://doi.org/10.1016/j.tips.2008.02.003

8. Xu L, Emery JF, Ouyang YB, Voloboueva LA, Giffard RG. Astrocyte targeted overexpression of Hsp72 or SOD2 reduces neuronal vulnerability to forebrain ischemia. Glia. 2010;58(9):1042-1049. https:// doi.org/10.1002/glia.20985

9. Rama Breton R, García Rodríguez JC. Excitotoxicity and Oxidative Stress in Acute Stroke. In: García Rodríguez JC, editor. Acute Ischemic Stroke. Rijeka, Croatia: InTech; 2011. p. 29-59. https://doi. org $/ 10.5772 / 28300$ 
10. Siesjo BK. Pathophysiology and treatment of focal cerebral ischemia. Part II: Mechanisms of damage and treatment. J Neurosurg. 1992;77(3):337-54. https://doi.org/10.3171/jns.1992.77.3.0337

11. Stonesifer C, Corey S, Ghanekar S, Diamandis Z, Acosta SA, Borlongan C V. Stem Cell Therapy for Abrogating Stroke-Induced Neuroinflammation and Relevant Secondary Cell Death Mechanisms. Prog Neurobiol. 2017;(158):94-131. https://doi.org/10.1016/j.pneurobio.2017.07.004

12. DiSabato D, Quan N, Godbout JP. Neuroinflammation:The Devil Is in the Details. J Neurochem. 2016;139((Suppl 2)):136-153. https://doi.org/10.1111/jnc.13607

13. Bandera E, Botteri M, Minelli C, Sutton A, Abrams KR, Latronico N. Cerebral blood flow threshold of ischemic penumbra and infarct core in acute ischemic stroke: A systematic review. Stroke. 2006;37(5):1334-9. https://doi.org/10.1161/01.STR.0000217418.29609.22

14. Moskowitz MA, Lo EH, Iadecola C. The Science of Stroke: Mechanisms in Search of Treatments. Neuron. 2010;67(2):181-98. https://doi.org/10.1016/j.neuron.2010.07.002

15. Jung S, Gilgen M, Slotboom J, El-Koussy M, Zubler C, Kiefer C, et al. Factors that determine penumbral tissue loss in acute ischaemic stroke. Brain. 2013;136(Pt 12):3554-60. https://doi.org/10.1093/ brain/awt 246

16. Catanese L, Tarsia J, Fisher M. Acute Ischemic Stroke Therapy Overview. Circ Res. 2017;120(3): 541-58. https://doi.org/10.1161/CIRCRESAHA.116.309278

17. Dugue R, Nath M, Dugue A, Barone FC. Roles of Pro- and Anti-inflammatory Cytokines in Traumatic Brain Injury and Acute Ischemic Stroke. In: Aranda Abreu GE, editor. Mechanisms of Neuroinflammation. Rijeka, Croatia: InTech; 2017. p. 211-261. https://doi.org/10.5772/ intechopen.70099

18. Radenovic L, Nenadic M, Ulamek-Kozioł M, Januszewski S, Czuczwar SJ, Andjus PR, et al. Heterogeneity in brain distribution of activated microglia and astrocytes in a rat ischemic model of Alzheimer's disease after 2 years of survival. Aging (Albany NY). 2020;12(12):12251-67. https://doi. org/10.18632/aging.103411

19. Jayaraj RL, Azimullah S, Beiram R, Jalal FY, Rosenberg GA. Neuroinflammation: Friend and foe for ischemic stroke. J Neuroinflammation. 2019;16(1):1-24. https://doi.org/10.1186/s12974-019-1516-2

20. Wang Q, Tang XN, Yenari MA. The inflammatory response in stroke. J Neuroimmunol. 2007; 184(1-2):53-68. https://doi.org/10.1016/j.jneuroim.2006.11.014

21. Yang C, Hawkins KE, Doré S, Candelario-Jalil E. Neuroinflammatory mechanisms of blood-brain barrier damage in ischemic stroke. Am J Physiol - Cell Physiol. 2019;316(2):C135-53. https://doi. org/10.1152/ajpcell.00136.2018

22. Gidday JM, Gasche YG, Copin JC, Shah AR, Perez RS, Shapiro SD, et al. Leukocyte-derived matrix metalloproteinase-9 mediates blood-brain barrier breakdown and is proinflammatory after transient focal cerebral ischemia. Am J Physiol - Hear Circ Physiol. 2005;289(2):H558-68. https://doi. org/10.1152/ajpheart.01275.2004

23. Stowe AM, Adair-Kirk TL, Gonzales ER, Perez RS, Shah AR, Park TS, et al. Neutrophil elastase and neurovascular injury following focal stroke and reperfusion. Neurobiol Dis. 2009;35(1):82-90. https://doi.org/10.1016/j.nbd.2009.04.006

24. Connolly ES, Winfree CJ, Springer TA, Naka Y, Liao H, Yan S Du, et al. Cerebral protection in homozygous null ICAM-1 mice after middle cerebral artery occlusion. Role of neutrophil adhesion in the pathogenesis of stroke. J Clin Invest. 1996;97(1):209-16. https://doi.org/10.1172/JCI118392

25. Yenari MA, Kunis D, Sun GH, Onley D, Watson L, Turner S, et al. Hu23F2G, an antibody recognizing the leukocyte CD 11/CD 18 integrin, reduces injury in a rabbit model of transient focal cerebral ischemia. Exp Neurol. 1998;153(2):223-33. https://doi.org/10.1006/exnr.1998.6876

26. Manrique-Castano D, Dzyubenko E, Borbor M, Vasileiadou P, Kleinschnitz C, Roll L, et al. Tenascin- $C$ preserves microglia surveillance and restricts leukocyte and, more specifically, $T$ cell infiltration of the ischemic brain. Brain Behav Immun. 2021;91:639-48. https://doi.org/10.1016/j. bbi.2020.10.016

27. Zhou W, Liesz A, Bauer H, Sommer C, Lahrmann B, Valous N, et al. Postischemic brain infiltration of leukocyte subpopulations differs among murine permanent and transient focal cerebral ischemia models. Brain Pathol. 2013;23(1):34-44. https://doi.org/10.1111/j.1750-3639.2012.00614.x

28. Feng Y, Liao S, Wei C, Jia D, Wood K, Liu Q, et al. Infiltration and persistence of lymphocytes during late-stage cerebral ischemia in middle cerebral artery occlusion and photothrombotic stroke models. J Neuroinflammation. 2017;14(1):1-12. https://doi.org/10.1186/s12974-017-1017-0 
29. Yilmaz G, Arumugam T V., Stokes KY, Granger DN. Role of T lymphocytes and interferon- $\gamma$ in ischemic stroke. Circulation. 2006;113(17):2105-12. https://doi.org/10.1161/CIRCULATIONAHA. 105.593046

30. Sekeljic V, Bataveljic D, Stamenkovic S, Ułamek M, Jabłoński M, Radenovic L, et al. Cellular markers of neuroinflammation and neurogenesis after ischemic brain injury in the long-term survival rat model. Brain Struct Funct. 2012;217(2):411-20. https://doi.org/10.1007/s00429-011-0336-7

31. Liesz A, Zhou W, Na SY, Hämmerling GJ, Garbi N, Karcher S, et al. Boosting regulatory T cells limits Neuroinflammation in permanent cortical stroke. J Neurosci. 2013;33(44):17350-62. https://doi. org/10.1523/JNEUROSCI.4901-12.2013

32. Xie L, Sun F, Wang J, Mao X, Xie L, Yang S-H, et al. mTOR Signaling Inhibition Modulates Macrophage/ Microglia-Mediated Neuroinflammation and Secondary Injury via Regulatory T Cells after Focal Ischemia. J Immunol. 2014;192(12):6009-19. https://doi.org/10.4049/jimmunol.1303492

33. ElAli A, LeBlanc NJ. The role of monocytes in ischemic stroke pathobiology: New avenues to explore. Front Aging Neurosci. 2016;8:1-7. https://doi.org/10.3389/fnagi.2016.00029

34. Qin X, Akter F, Qin L, Cheng J, Guo M, Yao S, et al. Adaptive Immunity Regulation and Cerebral Ischemia. Front Immunol. 2020;11:1-10. https://doi.org/10.3389/fimmu.2020.00689

35. Wang Y, Zhang JH, Sheng J, Shao A. Immunoreactive Cells After Cerebral Ischemia. Front Immunol. 2019;10:1-12. https://doi.org/10.3389/fimmu.2019.02781

36. Beuker C, Strecker JK, Rawal R, Schmidt-Pogoda A, Ruck T, Wiendl H, et al. Immune Cell Infiltration into the Brain After Ischemic Stroke in Humans Compared to Mice and Rats: a Systematic Review and Meta-Analysis. Transl Stroke Res. 2021;1-15 https://doi.org/10.1007/s12975-021-00887-4

37. Offner H, Hurn P. A Novel Hypothesis: Regulatory B Lymphocytes Shape Outcome from Experimental Stroke. Transl Stroke Res. 2011;23(1):1-7.

38. Ren X, Akiyoshi K, Dziennis S, Vandenbark AA, Herson PS, Hurn PD, et al. Regulatory B cells limit CNS inflammation and neurologic deficits in murine experimental stroke. J Neurosci. 2011;31(23): 8556-63. https://doi.org/10.1523/JNEUROSCI.1623-11.2011

39. Bodhankar S, Chen Y, Vandenbark AA, Murphy S, Offner H. IL-10-producing B-cells limit CNS inflammation and infarct volume in experimental stroke. Metab Brain Dis. 2013;28(3):375-386. https://doi.org/10.1007/s11011-013-9413-3

40. Chen Y, Bodhankar S, Murphy SJ, Vandenbark AA, Alkayed NJ, Offner H. Intrastriatal B-cell administration limits infarct size after stroke in B-cell deficient mice. Metab Brain Dis. 2012;27(4):487-93. https://doi.org/10.1007/s11011-012-9317-7

41. Doyle KP, Quach LN, Solé M, Axtell RC, Nguyen TV V., Soler-Llavina GJ, et al. B-lymphocytemediated delayed cognitive impairment following stroke. J Neurosci. 2015;35(5):2133-45. https:// doi.org/10.1523/JNEUROSCI.4098-14.2015

42. Schuhmann MK, Langhauser F, Kraft P, Kleinschnitz C. B cells do not have a major pathophysiologic role in acute ischemic stroke in mice. J Neuroinflammation. 2017;14(1):1-6. https://doi.org/10.1186/ s12974-017-0890-x

43. Schilling M, Besselmann M, Müller M, Strecker JK, Ringelstein EB, Kiefer R. Predominant phagocytic activity of resident microglia over hematogenous macrophages following transient focal cerebral ischemia: An investigation using green fluorescent protein transgenic bone marrow chimeric mice. Exp Neurol. 2005;196(2):290-7. https://doi.org/10.1016/j.expneurol.2005.08.004

44. Hawkins KE, DeMars KM, Alexander JC, de Leon LG, Pacheco SC, Graves C, et al. Targeting resolution of neuroinflammation after ischemic stroke with a lipoxin A4 analog: Protective mechanisms and long-term effects on neurological recovery. Brain Behav. 2017;7(5):1-14. https://doi.org/10.1002/ brb3.688

45. Dugue R, Barone FC. Ischemic, traumatic and neurodegenerative brain inflammatory changes. Future Neurol. 2016;11(1):77-96. https://doi.org/10.2217/fnl.16.5

46. Emmrich J V., Ejaz S, Neher JJ, Williamson DJ, Baron JC. Regional distribution of selective neuronal loss and microglial activation across the MCA territory after transient focal ischemia: Quantitative versus semiquantitative systematic immunohistochemical assessment. J Cereb Blood Flow Metab. 2015;35(1):20-7. https://doi.org/10.1038/jcbfm.2014.181

47. Sun M, Deng B, Zhao X, Gao C, Yang L, Zhao H, et al. Isoflurane preconditioning provides neuroprotection against stroke by regulating the expression of the TLR4 signalling pathway to alleviate microglial activation. Sci Rep. 2015;5(1):1-14. https://doi.org/10.1038/srepl1445 
48. Kuang X, Wang LF, Yu L, Li YJ, Wang YN, He Q, et al. Ligustilide ameliorates neuroinflammation and brain injury in focal cerebral ischemia/reperfusion rats: Involvement of inhibition of TLR4/ peroxiredoxin 6 signaling. Free Radic Biol Med. 2014;71:165-75. https://doi.org/10.1016/j. freeradbiomed.2014.03.028

49. Jin WN, Shi SXY, Li Z, Li M, Wood K, Gonzales RJ, et al. Depletion of microglia exacerbates postischemic inflammation and brain injury. J Cereb Blood Flow Metab. 2017;37(6):2224-36. https://doi. org/10.1177/0271678X17694185

50. Patabendige A, Singh A, Jenkins S, Sen J, Chen R. Astrocyte activation in neurovascular damage and repair following ischaemic stroke. Int J Mol Sci. 2021;22(8):4280. https://doi.org/10.3390/ijms 22084280

51. Szydlowska K, Zawadzka M, Kaminska B. Neuroprotectant FK506 inhibits glutamate-induced apoptosis of astrocytes in vitro and in vivo. J Neurochem. 2006;99(3):965-75. https://doi.org/10.1111/j.1471 $-4159.2006 .04136 . x$

52. Nowicka D, Rogozinska K, Aleksy M, Witte OW, Skangiel-Kramska J. Spatiotemporal dynamics of astroglial and microglial responses after photothrombotic stroke in the rat brain. Acta Neurobiol Exp (Wars). 2008;68(2):155-68.

53. Endoh M, Maiese K, Wagner J. Expression of the inducible form of nitric oxide synthase by reactive astrocytes after transient global ischemia. Brain Res. 1994;651(1-2):92-100. https://doi.org/10.1016 10006-8993(94)90683-1

54. Li M, Li Z, Yao Y, Jin WN, Wood K, Liu Q, et al. Astrocyte-derived interleukin-15 exacerbates ischemic brain injury via propagation of cellular immunity. Proc Natl Acad Sci U S A. 2017;114(3): E396-405. https://doi.org/10.1073/pnas.1612930114

55. Lakhan SE, Kirchgessner A, Hofer M. Inflammatory mechanisms in ischemic stroke: Therapeutic approaches. J Transl Med. 2009;7:1-11. https://doi.org/10.1186/1479-5876-7-97

56. Yang GY, Gong C, Qin Z, Liu XH, Lorris Betz A. Tumor necrosis factor alpha expression produces increased blood-brain barrier permeability following temporary focal cerebral ischemia in mice. Mol Brain Res. 1999;69(1):135-43. https://doi.org/10.1016/S0169-328X(99)00007-8

57. Boutin H, LeFeuvre RA, Horai R, Asano M, Iwakura Y, Rothwell NJ. Role of IL- $1 \alpha$ and IL-1 $\beta$ in ischemic brain damage. J Neurosci. 2001;21(15):5528-34. https://doi.org/10.1523/JNEUROSCI. 21-15-05528.2001

58. Denes A, Wilkinson F, Bigger B, Chu M, Rothwell NJ, Allan SM. Central and haematopoietic interleukin-1 both contribute to ischaemic brain injury in mice. DMM Dis Model Mech. 2013;6(4):1043-8. https://doi.org/10.1242/dmm.011601

59. Pérez-De Puig I, Miró F, Salas-Perdomo A, Bonfill-Teixidor E, Ferrer-Ferrer M, Márquez-Kisinousky L, et al. IL-10 deficiency exacerbates the brain inflammatory response to permanent ischemia without preventing resolution of the lesion. J Cereb Blood Flow Metab. 2013;33(12):1955-66. https://doi. org/10.1038/jcbfm.2013.155

60. Ooboshi H, Ibayashi S, Shichita T, Kumai Y, Takada J, Ago T, et al. Postischemic gene transfer of interleukin-10 protects against both focal and global brain ischemia. Circulation. 2005;111(7):913-9. https://doi.org/10.1161/01.CIR.0000155622.68580.DC

61. Veldhuis WB, Derksen JW, Floris S, Van der Meide PH, De Vries HE, Schepers J, et al. Interferonbeta blocks infiltration of inflammatory cells and reduces infarct volume after ischemic stroke in the rat. J Cereb Blood Flow Metab. 2003;23(9):1029-39. https://doi.org/10.1097/01.WCB.00000 80703.47016.B6

62. Ma M, Ma Y, Yi X, Guo R, Zhu W, Fan X, et al. Intranasal delivery of transforming growth factor-betal in mice after stroke reduces infarct volume and increases neurogenesis in the subventricular zone. BMC Neurosci. 2008;9:1-10. https://doi.org/10.1186/1471-2202-9-117

63. Pang L, Ye W, Che XM, Roessler BJ, Betz AL, Yang GY. Reduction of inflammatory response in the mouse brain with adenoviral-mediated transforming growth factor- $\beta 1$ expression. Stroke. 2001;32(2): 544-52. https://doi.org/10.1161/01.STR.32.2.544

64. Iadecola C, Salkowski CA, Zhang F, Aber T, Nagayama M, Vogel SN, et al. The transcription factor interferon regulatory factor 1 is expressed after cerebral ischemia and contributes to ischemic brain injury. J Exp Med. 1999;189(4):719-27. https://doi.org/10.1084/jem.189.4.719 
65. Nurmi A, Lindsberg PJ, Koistinaho M, Zhang W, Juettler E, Karjalainen-Lindsberg ML, et al. Nuclear Factor-кB Contributes to Infarction after Permanent Focal Ischemia. Stroke. 2004;35(4):987-91. https://doi.org/10.1161/01.STR.0000120732.45951.26

66. Collino M, Aragno M, Mastrocola R, Benetti E, Gallicchio M, Dianzani C, et al. Oxidative stress and inflammatory response evoked by transient cerebral ischemia/reperfusion: Effects of the PPAR- $\alpha$ agonist WY14643. Free Radic Biol Med. 2006;41(4):579-89. https://doi.org/10.1016/j. freeradbiomed.2006.04.030

67. Kapadia R, Tureyen K, Bowen KK, Kalluri H, Johnson PF, Vemuganti R. Decreased brain damage and curtailed inflammation in transcription factor CCAAT/enhancer binding protein $\beta$ knockout mice following transient focal cerebral ischemia. J Neurochem. 2006;98(6):1718-31. https://doi. org/10.1111/j.1471-4159.2006.04056.x

68. Satriotomo I, Bowen KK, Vemuganti R. JAK2 and STAT3 activation contributes to neuronal damage following transient focal cerebral ischemia. J Neurochem. 2006;98(5):1353-68. https://doi. org/10.1111/j.1471-4159.2006.04051.x

69. Iwashita A, Muramatsu Y, Yamazaki T, Muramoto M, Kita Y, Yamazaki S, et al. Neuroprotective efficacy of the peroxisome proliferator-activated receptor $\delta$-selective agonists in vitro and in vivo. J Pharmacol Exp Ther. 2007;320(3):1087-96. https://doi.org/10.1124/jpet.106.115758

70. Tureyen K, Kapadia R, Bowen KK, Satriotomo I, Liang J, Feinstein DL, et al. Peroxisome proliferator-activated receptor- $\gamma$ agonists induce neuroprotection following transient focal ischemia in normotensive, normoglycemic as well as hypertensive and type-2 diabetic rodents. J Neurochem. 2007;101(1):41-56. https://doi.org/10.1111/j.1471-4159.2006.04376.x

71. Yi JH, Park SW, Kapadia R, Vemuganti R. Role of transcription factors in mediating post-ischemic cerebral inflammation and brain damage. Neurochem Int. 2007;50(7-8):1014-27. https://doi. org/10.1016/j.neuint.2007.04.019

72. Jauch EC, Saver JL, Adams HP, Bruno A, Connors JJB, Demaerschalk BM, et al. Guidelines for the early management of patients with acute ischemic stroke: A guideline for healthcare professionals from the American Heart Association/American Stroke Association. Stroke. 2013;44(3):870-947. https://doi. org/10.1161/STR.0b013e318284056a

73. Clinical Guidelines for Stroke Management. https://informme.org.au/en/Guidelines/ClinicalGuidelines-for-Stroke-Management-2017 [Accessed on 09 Aug 2021]

74. Rudd AG, Bowen A, Young GR, James MA. The latest national clinical guideline for stroke. Clin Med. 2017;17(2):154-9. https://doi.org/10.7861/clinmedicine.17-2-154

75. Choudhary RC, Shoaib M, Sohnen S, Rolston DM, Jafari D, Miyara SJ, et al. Pharmacological Approach for Neuroprotection After Cardiac Arrest-A Narrative Review of Current Therapies and Future Neuroprotective Cocktail. Front Med. 2021;8:1-14. https://doi.org/10.3389/fmed.2021.636651

76. Popa-Wagner A, Petcu EB, Capitanescu B, Hermann DM, Radu E, Gresita A. Ageing as a risk factor for cerebral ischemia: Underlying mechanisms and therapy in animal models and in the clinic. Mech Ageing Dev. 2020;190:111312. https://doi.org/10.1016/j.mad.2020.111312

77. Tajiri N, Acosta S, Glover LE, Bickford PC, Jacotte Simancas A, Yasuhara T, et al. Intravenous grafts of amniotic fluid-derived stem cells induce endogenous cell proliferation and attenuate behavioral deficits in ischemic stroke rats. PLoS One. 2012;7(8):1-10. https://doi.org/10.1371/journal. pone.0043779

78. Acosta SA, Tajiri N, Shinozuka K, Ishikawa H, Grimmig B, Diamond D, et al. Long-Term Upregulation of Inflammation and Suppression of Cell Proliferation in the Brain of Adult Rats Exposed to Traumatic Brain Injury Using the Controlled Cortical Impact Model. PLoS One. 2013;8(1):1-8. https://doi. org/10.1371/journal.pone.0053376

79. Jin R, Yang G, Li G. Inflammatory mechanisms in ischemic stroke: role of inflammatory cells. J Leukoc Biol. 2010;87(5):779-89. https://doi.org/10.1189/jlb.1109766

80. Weiland J, Beez A, Westermaier T, Kunze E, Sirén AL, Lilla N. Neuroprotective strategies in aneurysmal subarachnoid hemorrhage (aSAH). Int J Mol Sci. 2021;22(11):5442. https://doi.org/10.3390/ ijms22115442

81. Malone K, Amu S, Moore AC, Waeber C. The immune system and stroke: from current targets to future therapy. Immunol Cell Biol. 2019;97(1):5-16. https://doi.org/10.1111/imcb.12191 
82. Jiang J, Yu Y. Small molecules targeting cyclooxygenase/prostanoid cascade in experimental brain ischemia: Do they translate? Med Res Rev. 2021;41(2):828-57. https://doi.org/10.1002/med.21744

83. Rawish E, Nording H, Münte T, Langer HF. Platelets as Mediators of Neuroinflammation and Thrombosis. Front Immunol. 2020;11:1-16. https://doi.org/10.3389/fimmu.2020.548631

84. Pluta R, Lossinsky AS, Walski M, Wisniewski HM, Mossakowski MJ. Platelet occlusion phenomenon after short- and long-term survival following complete cerebral ischemia in rats produced by cardiac arrest. J Hirnforsch. 1994; 35(4), 463-71.

85. Dos Santos I, DIas M, Gomes-Leal W. Microglial activation and adult neurogenesis after brain stroke. Neural Regen Res. 2021;16(3):456-9. https://doi.org/10.4103/1673-5374.291383

86. Caffes N, Kurland DB, Gerzanich V, Marc Simard J. Glibenclamide for the treatment of ischemic and hemorrhagic stroke. Int J Mol Sci. 2015;16(3):4973-84. https://doi.org/10.3390/ijms16034973

87. Yang X, Wang Z, Jia X. Neuroprotection of Glibenclamide against Brain Injury after Cardiac Arrest via Modulation of NLRP3 Inflammasome. Conf Proc IEEE Eng Med Biol Soc. 2019;4209-4212. https:// doi.org/10.1109/EMBC.2019.8857285

88. Kämäräinen A, Virkkunen I, Silfvast T, Tenhunen J. Statins for post resuscitation syndrome. Med Hypotheses. 2009;73(1):97-9. https://doi.org/10.1016/j.mehy.2009.01.021

89. Gupta YK, Chauhan A. Potential of immunosuppressive agents in cerebral ischaemia. Indian J Med Res. 2011;133(1):15-26.

90. Sandercock PA, Soane T. Corticosteroids for acute ischaemic stroke. Cochrane Database Syst Rev. 2011;(9):CD000064. https://doi.org/10.1002/14651858.CD000064.pub2

91. Wintzer S, Heckmann JG, Huttner HB, Schwab S. Dexamethasone in Patients with Spontaneous Intracerebral Hemorrhage: An Updated Meta-Analysis. Cerebrovasc Dis. 2020;49(5):495-502. https://doi.org/10.1159/000510040

92. Yimer EM, Hishe HZ, Tuem KB. Repurposing of the $\beta$-lactam antibiotic, ceftriaxone for neurological disorders: A review. Front Neurosci. 2019;13:2260-71. https://doi.org/10.3389/fnins.2019.00236

93. Tan HY, Ng KY, Koh RY, Chye SM. Pharmacological Effects of Melatonin as Neuroprotectant in Rodent Model: A Review on the Current Biological Evidence. Cell Mol Neurobiol. 2020;40(1):25-51. https:// doi.org/10.1007/s10571-019-00724-1

94. Niles LP, Armstrong KJ, Rincón Castro LM, Dao C V., Sharma R, McMillan CR, et al. Neural stem cells express melatonin receptors and neurotrophic factors: Colocalization of the MTl receptor with neuronal and glial markers. BMC Neurosci. 2004;5:1-9. https://doi.org/10.1186/1471-2202-5-41

95. Sadanandan N, Cozene B, Cho J, Park YJ, Saft M, Gonzales-Portillo B, et al. Melatonin-A potent therapeutic for stroke and stroke-related dementia. Antioxidants. 2020;9(8):1-15. https://doi.org/10.3390/ antiox 9080672

96. Liu ZJ, Ran YY, Qie SY, Gong WJ, Gao FH, Ding ZT, et al. Melatonin protects against ischemic stroke by modulating microglia/macrophage polarization toward anti-inflammatory phenotype through STAT3 pathway. CNS Neurosci Ther. 2019;25(12):1353-62. https://doi.org/10.1111/cns.13261

97. Moinard C, Cynober L, de Bandt JP. Polyamines: Metabolism and implications in human diseases. Clin Nutr. 2005;24(2):184-97. https://doi.org/10.1016/j.clnu.2004.11.001

98. Neis VB, Rosa PB, Olescowicz G, Rodrigues ALS. Therapeutic potential of agmatine for CNS disorders. Neurochem Int. 2017;108:318-31. https://doi.org/10.1016/j.neuint.2017.05.006

99. Abe K, Abe Y, Saito H. Agmatine suppresses nitric oxide production in microglia. Brain Res. 2000;872(1-2):141-8. https://doi.org/10.1016/S0006-8993(00)02517-8

100. Ahn SK, Hong S, Park YM, Choi JY, Lee WT, Park KA, et al. Protective effects of agmatine on lipopolysaccharide-injured microglia and inducible nitric oxide synthase activity. Life Sci. 2012;91 (25-26):1345-50. https://doi.org/10.1016/j.1fs.2012.10.010

101. Selakovic V, Arsenijevic L, Jovanovic M, Sivcev S, Jovanovic N, Leontijevic M, et al. Functional and pharmacological analysis of agmatine administration in different cerebral ischemia animal models. Brain Res Bull. 2019;146:201-12. https://doi.org/10.1016/j.brainresbull.2019.01.005

102. Sahin C, Albayrak O, Akdeniz TF, Akbulut Z, Yanikkaya Demirel G, Aricioglu F. Agmatine Reverses Sub-chronic Stress induced Nod-like Receptor Protein 3 (NLRP3) Activation and Cytokine Response in Rats. Basic Clin Pharmacol Toxicol. 2016;119(4):367-75. https://doi.org/10.1111/bcpt.12604 
103. Kim JY, Lee YW, Kim JH, Lee WT, Park KA, Lee JE. Agmatine attenuates brain edema and apoptotic cell death after traumatic brain injury. J Korean Med Sci. 2015;30(7):943-52. https://doi.org/10.3346/ jkms.2015.30.7.943

104. Wang J, Yao J, Liu Y, Huang L. Targeting the gasdermin D as a strategy for ischemic stroke therapy. Biochem Pharmacol. 2021;188:114585. https://doi.org/10.1016/j.bcp.2021.114585

105. Loddick SA, Rothwell NJ. Neuroprotective effects of human recombinant interleukin-1 receptor antagonist in focal cerebral ischaemia in the rat. J Cereb Blood Flow Metab. 1996;16(5):932-40. https://doi.org/10.1097/00004647-199609000-00017

106. Yepes M, Brown SAN, Moore EG, Smith EP, Lawrence DA, Winkles JA. A soluble Fnl4-Fc decoy receptor reduces infarct volume in a murine model of cerebral ischemia. Am J Pathol. 2005;166(2):511-20. https://doi.org/10.1016/S0002-9440(10)62273-0

107. Vendrame M, Gemma C, Pennypacker KR, Bickford PC, Davis Sanberg C, Sanberg PR, et al. Cord blood rescues stroke-induced changes in splenocyte phenotype and function. Exp Neurol. 2006;199(1):191-200. https://doi.org/10.1016/j.expneurol.2006.03.017

108. Walker PA, Shah SK, Jimenez F, Gerber MH, Xue H, Cutrone R, et al. Intravenous multipotent adult progenitor cell therapy for traumatic brain injury: Preserving the blood brain barrier via an interaction with splenocytes. Exp Neurol. 2010;225(2):341-52. https://doi.org/10.1016/j.expneurol.2010.07.005

109. Padma Srivastava M V., Bhasin A, Bhatia R, Garg A, Gaikwad S, Prasad K, et al. Efficacy of minocycline in acute ischemic stroke: A single-blinded, placebo-controlled trial. Neurol India. 2012;60(1):23-8. https://doi.org/10.4103/0028-3886.93584

110. Marcet P, Santos N, Borlongan C V. When friend turns foe: central and peripheral neuroinflammation in central nervous system injury. Neuroimmunol Neuroinflamm. 2017;4:82-92. https://doi. org/10.20517/2347-8659.2017.07

111. Tuazon JP, Castelli V, Borlongan C V. Drug-like delivery methods of stem cells as biologics for stroke. Expert Opin Drug Deliv. 2019;16(8):823-33. https://doi.org/10.1080/17425247.2019.1645116

112. Duncan T, Valenzuela M. Alzheimer's disease, dementia, and stem cell therapy. Stem Cell Res Ther. 2017;8(1):1-9. https://doi.org/10.1186/s13287-017-0567-5

113. Suda S, Nito C, Yokobori S, Sakamoto Y, Nakajima M, Sowa K, et al. Recent advances in cell-based therapies for ischemic stroke. Int J Mol Sci. 2020;21(18):1-24. https://doi.org/10.3390/ijms21186718

114. Tajiri N, Staples M, Acosta S, Pabon M, Dailey T, Kaneko Y, Borlongan CV. Stem Cell Therapies in Neurology. In: Ratajczak MZ, editor. Adult Stem Cell Therapies: Alternatives to Plasticity, Stem Cell Biology and Regenerative Medicine. New York, United States: Humana Press; 2014. p. 117-136. https://doi.org/10.1007/978-1-4939-1001-4_7

115. Nair M, Sandhu SS, Sharma AK. Induced Pluripotent Stem Cell Technology: A Paradigm Shift in Medical Science for Drug Screening and Disease Modeling. Curr Med Chem. 2017; 24(39):43684398. https://doi.org/10.2174/0929867324666170727100508

116. Subedi L, Gaire BP, Parveen A, Kim SY. Nitric Oxide as a Target for Phytochemicals in AntiNeuroinflammatory Prevention Therapy. Int J Mol Sci. 2021;22(9):4771. https://doi.org/10.3390/ ijms22094771

117. Pluta R, Januszewski S, Czuczwar SJ. Myricetin as a promising molecule for the treatment of post-ischemic brain neurodegeneration. Nutrients. 2021;13(2):1-16. https://doi.org/10.3390/nul3020342

118. Huang C, Wu J, Chen D, Jin J, Wu Y, Chen Z. Effects of sulforaphane in the central nervous system. Eur J Pharmacol. 2019;853:153-68. https://doi.org/10.1016/j.ejphar.2019.03.010

119. Parvez MK. Natural or Plant Products for the Treatment of Neurological Disorders: Current Knowledge. Curr Drug Metab. 2018; 19(5), 424-428. https://doi.org/10.2174/1389200218666170710190249

120. Fei F, Su N, Li X, Fei Z. Neuroprotection mediated by natural products and their chemical derivatives. Neural Regen Res. 2020;15(11):2008-15. https://doi.org/10.4103/1673-5374.282240

121. Ułamek-Kozioł M, Czuczwar SJ, Januszewski S, Pluta R. Substantiation for the use of curcumin during the development of neurodegeneration after brain ischemia. Int J Mol Sci. 2020;21(2):1-17. https:// doi.org/10.3390/ijms21020517 
